\title{
AN ANALYSIS OF THE TRAGIC EVENTS WHICH OCCURRED AT AN INAUGURATION PARTY ORGANIZED BY THE STUDENT GOVERNMENT OF THE UNIVERSITY OF SCIENCE AND TECHNOLOGY IN BYDGOSZCZ DURING THE 2015/2016 ACADEMIC YEAR
}

\author{
Przemyslaw Paciorek ${ }^{1,2}$, Krzysztof Wisniewski ${ }^{1,2}$, Filip Oleszak ${ }^{3}$, Bartosz Zawada ${ }^{3}$ \\ ${ }^{1}$ Department of Cardiology and Internal Medicine, Nicolaus Copernicus University, Collegium Medicum, Bydgoszcz, Poland \\ ${ }^{2}$ Bydgoszcz The Voivodship Emergency Medical Service, Bydgoszcz, Poland \\ ${ }^{3}$ Poznan University of Medical Sciences, Poznan, Poland
}

\begin{abstract}
In this article, the authors analysed the tragic events which took place at an inauguration party organized by the student government of the University of Science and Technology in Bydgoszcz during the 2015/2016 academic year. As a result of crowd panic which occurred during "initiation ceremonies", three young students died.
\end{abstract}

KEY WORDS: mass party, crowd panic, mass panic, cardiopulmonary resuscitation, chest immobilization, student party

Disaster Emerg Med J 2017; 2(2): 84-90

\section{INTRODUCTION}

The Jan and Jedrzej Śniadecki University of Science and Technology (UTP) in in Bydgoszcz (Fig. 1) is a multidisciplinary institution which provides education to many prospective engineers. It is the only school in the region which integrates technological, natural, agricultural, economic and artistic studies. In its 63 years of existence, over 53,000 graduates have passed through the school's program. Currently, over 9,000 students are studying full-time and part-time, including students of doctoral and post-graduate studies. UTP occupies a high position in the ranks of universities, especially among those in which the preparation of graduates to obtain good careers is highly regarded. In the 2006 "Newsweek" ranking, the university was awarded first place among top agricultural universities. UTP has showed tremendous progression and dynamic development on many levels in recent years.

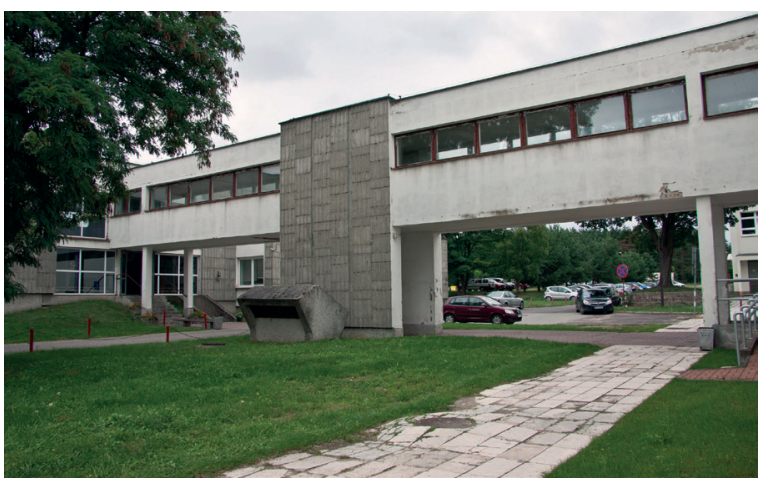

FIGURE 1. Conjoining hallway between buildings in UTP in Bydgoszcz on 7 Kaliskiego Street 
On October 14, 2015, on the UTP campus, on 7 Kaliskiego Street in Bydgoszcz, as every year, the student government organized a party to mark the inauguration of the 2015/16 academic year, commonly referred to as "otrzesiny", directly translated as "the shakening". The organizers did not declare this a mass event [1-4], a practice continued from previous years, based on the territorial autonomy of the University as defined in the Law on Higher Education. Each year prior to the event, the University's student government receives verbal consent from the rector and vice-rector in order to be able to coordinate the inauguration party.

The basis on which an event qualifies as a mass event is defined in the Law of March 20, 2009 [5]. This law reviews the safety of mass events, and describes any event of a similar scale to the student's "shakening" as a mass event. Although legislators use this term to encompass mass entertainment events, as well as mass sporting functions, it excludes events such as theatres, operas, operettas, philharmonic orchestras, cinemas, museums, libraries, cultural centres, art galleries, events organized by employers, sports events for the disabled, as well as sporting competitions organized for children and youth $[5,6]$. To qualify as a mass event, the number of individuals participating must exceed 1,000 for events specifically taking place in a stadium or in an area enabling it to be conducted, or exceed 5,000 for when the event is set to take place in a sports hall or other similar building. The maximum permitted attendance for each event depends on the capacity of the venue in which the event is supposed to take place. Exceeding this limit may result in the criminal prosecution of those organizing the event. These rules do not apply to free events coordinated by organizations under a central governmental administration when the events are set to take place within closed areas managed by the said administration. All of these requirements must be met together in order to be valid. During this event, the central authority is for example, the Minister of Science and Higher Education managing UTP. Most importantly, the subordinate organization is not the student government. (Judgement of the Provincial Court of Administration from March 20, 2006, VI SAWa 878/05).

\section{EVENT ANALYSIS}

For the past 15 years, in accordance with university tradition, an inauguration party has taken place annually at the beginning of each academic year on the UTP campus on 7 Kaliskiego Street in Bydgoszcz. In the years prior, the inauguration festivities took place in the University's main hall. However, in 2015, due to renovations, a new venue was chosen for the yearly celebrations. The new event space consisted of two small rooms, each in a separate building, joined together by a narrow constricted hallway.

Upon entrance, each attendee was required to pay an admission fee which, unbeknownst to the organizers of the party, qualified this as a mass event. Additionally, without the formal consent of the university, alcohol was being sold and distributed on university grounds; a second reason to qualify this as a mass event. As already mentioned, the party took place in two rooms in two different buildings connected by a hallway. This hallway, roughly 20 meters long and 2 meters wide, was suspended between the two buildings a few meters off the ground (Fig. 2, 3). In one of these rooms, alcohol was being sold, while the other building contained the restrooms, forcing attendees to use this hallway to travel between the two buildings. The passageway was also regularly occupied by attendees as a dedicated smoking area. As

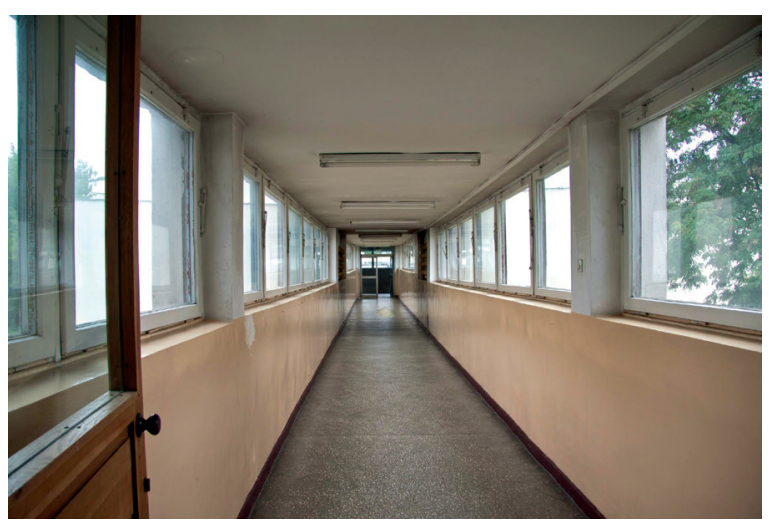

FIGURE 2. Conjoining hallway between buildings in UTP in Bydgoszcz on 7 Kaliskiego Street

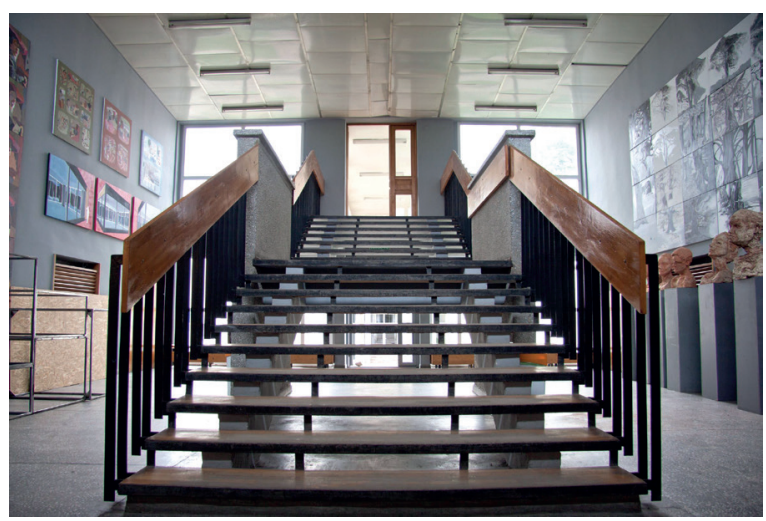

FIGURE 3. University of Science and Technology in Bydgoszcz (UTP) 
the hours went on, more and more students arrived at the function. It is estimated that, at the height of party, there were well over 1,200 people present, and, according to some sources, even upwards of 2000. To the surprise of the organizers, more and more people showed up to the party, ultimately forming an overwhelmingly large mass of people, notably in the previously mentioned connecting hallway. As the organizers of the event lost control of the amount of people in attendance, the crowd grew larger and the passageway became a significant chokepoint as attendees moved from one building to buy alcohol and to the other building to use the toilets, all while the passage was continuously being used as a smoking area. Due to the cold weather at the time of the function, none of the attendees considered leaving the building to smoke, despite the fact that there were nearby emergency exits just under the passageway. At one point, the traffic from either side of the hallway increased with attendees who were under the influence of alcohol. As the carbon dioxide level in the hallway grew, attendees described that there was a "lack of air" in the hallway. All it took was for one individual to collapse for the crowd to erupt in panic for fear of their lives.

One definition describes panic as a sudden, uncontrolled and unreasonable fear that can embrace an individual or a crowd of people. Panic sometimes erupts in the absence of real danger, creating the illusion of the presence of a threat, in the same way yelling "fire" may invoke panic in a crowd. Many historical examples exist in which mass panic played an integral part in such chaotic episodes. One of these was the "Love Parade" which occurred on June 24, 2010 in Duisburg, Germany. The event was attended by around 1.4 million people, and, as a result of mass panic in a tunnel leading to the event, 21 people died and 511 were injured. Security guards prevented attendees from exiting the tunnel resulting in chaos and panic breaking out amongst the crowd. Another example of a similar tragedy occurred on November 22, 2010, in Cambodia's capital, Phnom Penh, during the "Water Festival". Roughly 2 million people were in attendance when suddenly panic erupted on a bridge, causing terrified people to push each other off into the river below. All of this panic was allegedly precipitated by the fainting of one individual, and it is possible that part of the panic resulted from the crowd believing that there was an ongoing terrorist attack. As chaos took over the crowd, people were pushed into the
Mekong river, resulting in 456 deaths, and 700 injuries, mostly as a result of drowning.

However, returning to the panic which erupted on the UTP campus in Bydgoszcz, at 00:56 on October 15, 2015, a young man identifying himself as the organizer of the event called 112 and was connected to an emergency medical dispatcher. The following conversation was: "Please bring an ambulance, we have a small problem, there is a fight among over 20 people. Building 3-1 at UTP, $7 \mathrm{Ka}-$ liskiego street... Under the conjoining hallway... straight through the gate. 20 people injured, 20 people, they fell from the stairs, they fell from the stairs. That is what the security is telling us, we're locked in another part of the building with the money... security locked us in here." As the medical dispatcher collected this information, he immediately dispatched two basic emergency medical service (EMS) teams from the Provincial Emergency Medical Service in Bydgoszcz, and notified the police officers on duty about the call. The EMS teams that were dispatched (P-4 and P-11) were stationed $3 \mathrm{~km}$ away from the location of the event, allowing them to arrive at the scene much sooner than the police patrol. During the night there were countless other calls to the emergency number 112 and 999, and practically each call was different and attributed a different cause as to why to the tragedy which had occurred. Here is an example of one of the calls at 00:57: "Please send an ambulance quickly, to $7 \mathrm{Ka}$ liskiego street. There are injured people, many injured people. Everyone trampled each other, they fell from the stairs. Please come quickly, this is the scene of a massacre, security is not doing anything, everyone is only watching... please come quickly... please, quickly". At 01:02, in accordance with procedures, the medical dispatcher notified the Bydgoszcz Centre for Crisis Management, and soon after assigned the leader of the EMS team P-11 as the onsite medical coordinator until a specialized EMS unit with a physician had arrived. The leader of the first responding P-11 EMS team recalls: "Upon arrival to the scene, there was a crowd of hundreds of people chaotically evacuating from the university (security did not have any control over the situation). Outside, three people were injured, two conscious and one experiencing sudden cardiac arrest which we immediately treated with the help of team P-4." This was the first of three resuscitation attempts on the scene. At 01:05 another call to the 999 emergency number came with information about two 
further victims, and it is as follows: "...We have two more injured people, they got gassed, they are not breathing. It is a man and a woman... There's too few ambulances... there's about 1,000 people here..." The gas referred to in the phone call was pepper spray, which was used at the scene of the incident. Pepper spray works by triggering a strong burning sensation in a person's eyes making it difficult to keep one's eyes open, as well as provoking difficulty breathing and confusion. This spray is useful in confronting people under the influence of alcohol, narcotics, or under the influence of large amounts of adrenaline (hyper-stimulated). Law-enforcement services are authorized to use physical force in the form of incapacitating manoeuvres or similar defense techniques, handcuffs, or hand-held pepper spray launchers in the event of a threat to the property entrusted with protection, as well as in the event of repelling an attack. The use of pepper spray in this situation remains questionable as it may have aggravated the panic and worsened the ensuing chaos. At 01:10, the medical dispatcher decided to inform the regional fire department on duty about the situation due to having a general lack of knowledge on the cause and character of the event and, since EMS teams reported that they were unable to access the UTP buildings. The situation in which the EMS teams found themselves in was dangerous and for a long time they were operating in what is known to combat medics as the "red zone". The leader of EMS team P-11 relates: "Immediate entry into the building was not possible, the pressure of the crowd still inside the building moved to the front door. Several security guards were unable to control the situation...". The EMS personnel, knowing that they were operating in dangerous circumstances and that they did not have the support of the Police and Fire Department, decided to forcibly enter the building and break through the crowd of students to get to the injured and in order to verify the nature and size of this incident. In the lobby of the building, the EMS teams found two ongoing resuscitation attempts being carried out by medically trained attendees of the event assisted by surrounding witnesses. The EMS team split up and one team member went to assist in each of the resuscitations. In the meantime, 10 more EMS teams from Bydgoszcz were dispatched to the UTP campus, and in total, 12 EMS teams were present on the scene. At 01:13, a physician from the specialized EMS team S-5 from the Provincial Medical Service in
Bydgoszcz took over as the onsite medical coordinator. At 01:20, the medical dispatcher began informing the regional hospitals of the possibility of a mass casualty event. The hospitals informed were: University Hospital No. 1, University Hospital No. 2, the 10th Military Clinical Hospital (WSK X) and the City Hospital. The dispatcher's words were: "Please prepare yourselves to admit many victims. The cause of the event is unclear - possibly a mass fight, building collapse, or mass trampling. Three victims are undergoing resuscitation". The Emergency Department in WSK X did not respond to initial radio contact despite multiple attempts made by the medical dispatcher. The dispatcher was forced to contact the Emergency Department by phone to relay the information regarding the event to the hospital staff. For the entire duration of the rescue operation, there was no radio contact with the Emergency Department at WSK X, which complicated the operations of the medical dispatcher, as well as EMS teams. After obtaining information regarding the possibility of a mass event, University Hospital No. 1 was the only hospital which immediately launched its internal procedures and preparations for a mass casualty event. At 01:25, the medical dispatcher received a phone call from an on-duty fire-fighter, which further complicated the work of the emergency alert center in Bydgoszcz. The dispatcher was informed that, at the scene of the event, there were 7 resuscitation attempts ongoing, and that he would like to request more EMS teams to come to the UTP campus. This message disrupted the dispatcher as the information he had from the onsite medical coordinator was that there were $12 \mathrm{EMS}$ teams present and 3 active resuscitation attempts. In order to validate information, the dispatcher contacted the onsite medical coordinator yet again to confirm that there were in fact 3 resuscitations, which turned out to be correct. This, however, took up a few minutes of precious time during the rescue attempt. Where did the fire-fighters receive information of 7 resuscitations? Should the fire-fighter concerned have been able to dispatch EMS teams? These are, of course, rhetorical questions. At 01:30, the medical dispatcher once again called the on-call police officer asking for more onsite resources. An emergency medical responder who was inside the building relates: "Carrying out the operation was made more difficult by the fact that the victims were widely dispersed (since the event was held in two buildings connected by a narrow link), difficult to access, not 
responding to commands, often aggressive and hindering our actions. Efforts were further complicated by the presence of a large amount of people (mostly under the influence of alcohol). The event security guards did not have the crowd under control, and, despite many urges, the police was not able to reach the inside of the buildings. From the information I have from the other teams, I know that the police arrived very late." At 01:32, the first victims were transported to nearby hospitals. Every EMS team had clear guidelines from the main medical dispatcher to which hospital they should transport their victim. Due to the dispersal of the victims, the victims were not transported to only one hospital but were able to be equally distributed amongst the regional hospitals. At 01:52, the EMS team P-8 related this information to the medical dispatcher: "... We have the situation on Kaliskiego street under control..." At 02:20, the last EMS team, S-5, with the onsite medical coordinator left the scene of the event, and through the radio the coordinator said: "S-5 to every team taking part in this rescue, thank you... great work".

Analysis of the causative factor behind the eruption of panic points to the "bottleneck" of the hallway linking the two buildings "running out of air". It is most likely that the fainting of one individual caused the crowd to fall into panic and chaos. The people who were trapped in this hallway were being pushed by the crowds of people from both sides and as a result started breaking the windows along the length of the hallway. All injuries suffered by victims were established by medical rescuers at the scene of the incident and subsequently confirmed by imaging studies at hospital emergency departments. The injuries were indicative of violent compressions consistent with trauma due to human trampling.

\section{THE VICTIMS}

The Provincial Emergency Medical Service (WSPR) in Bydgoszcz has a total of 16 ambulances at its disposal. They are dispersed citywide with two of them located in Solec Kujawskie and Dobrcz; neighborhoods located on the peripheries of Bydgoszcz. This wide distribution ensures fast access to patients all throughout Bydgoszcz. Of these 16 ambulances, 12 are comprised of two-person basic rescue units, while the remaining 4 are specialized teams consisting of three people. 12 ambulances from the WSPR in Bydgoszcz participated in the rescue efforts at the UTP university campus on 7 Kaliskiego street: 9 two-person basic rescue units (P-1, P-2, P-3, P-4, P-8, P-9, P-10, P-11, P-12) and 3 specialized three-member teams (S-2, S-4, S-5). At the scene of the incident, these ambulance responders secured a total of 8 victims, including three of which suffered sudden cardiac arrest. As commanded by the medical dispatcher, patients were transported to 4 local hospitals. Three women, including one of the victims of cardiac arrest, were transported to Antoni Jurasz University Hospital No. 1. In addition, 5 more victims arrived separately at this hospital's Emergency Department by their own means of transport. The next two victims, a man with cardiac arrest, and a woman with bodily injuries, were transferred to Jan Biziel University Hospital No. 2. The following two victims were women suffering from bodily injuries who were transported to the 10th Military Clinical Hospital's emergency department. Additionally, two more individuals reported to the same emergency department independently by their own means of transport. Finally, two women, including one cardiac arrest victim, were transported to the emergency department of the City Hospital of Bydgoszcz in accordance with the medical dispatchers' orders. Two more individuals arrived to this hospital's emergency department via independent transportation.

The first victim suffering from cardiac arrest was 20 year old female who was found in front of the building at the scene of the incident. Emergency responders determined asystole as the cause of cardiac arrest on the scene and resuscitation according to the ALS guidelines algorithm was initiated by Medical Rescue Team P-4 and then taken over by Medical Rescue Team S-4. Additionally, upon physical examination, traumatic injury to the patient's left jaw was observed. Continuous resuscitation was provided with the aid of a mechanical chest compressor and this patient was transported to University Hospital No. 1. In the emergency department, resuscitation was continued for a considerable amount of time, with no hemodynamic response, and death was pronounced by the doctor on duty. An autopsy revealed suffocation due to violent compression of the thoracic cavity.

The next victim of cardiac arrest was 19 year old male who was found by Medical Rescue Team P-11. Initial resuscitation was commenced on the scene by witnesses and medically trained individuals attending the party and CPR was continued by the first member of Medical Rescue Team P-11 in accordance with the 
ALS algorithm. Cardiac arrest due to asystole was confirmed. Resuscitation was continued and the patient was transported to University Hospital No. 2 on assisted ventilation. Further imaging studies revealed a generalized cerebral oedema and irregularities in the bodies and processes of the $\mathrm{C} 3$ and $\mathrm{C} 5$ vertebra. The patient was urgently admitted to the Department of Neurosurgery and later transferred to the Intensive Care Unit. He died on October 17, 2015 without having ever regained consciousness. An autopsy revealed a cerebral oedema due to hypoxia as a direct result of traumatic compression of the thoracic cavity. The 19-year-old's family elected to donate their son's organs for transplantation. "His death was not pointless, he provided four other people with life" stated the mother of the dead boy.

The third victim of cardiac arrest was found in the middle of the building with ongoing resuscitation already being performed by witnesses and medically trained individuals. Resuscitation was continued by the second member of Medical Rescue Team P-11 upon arrival, and, finally, Medical Rescue Team P-9 assumed control of the resuscitative efforts in accordance with the ALS algorithm. Cardiac arrest due to asystole was confirmed. Resuscitation was continued and the patient was transported to the Bydgoszcz City Hospital on assisted ventilation. Further imaging studies found a subarachnoid haemorrhage, a cerebral oedema, as well as numerous rib fractures consistent with thoracic cavity compression. The patient was subsequently admitted to the Intensive Care Unit. She died on November 1, 2015. An autopsy of this patient confirmed a cerebral oedema due to hypoxia as a result of traumatic compression of the thoracic cavity.

The results of all of the autopsy sections were comparable in their findings. They provided very similar evidence as to the cause of death, and demonstrated signs of compression of the thorax and extensive hypoxia. Presumably, cardiac arrest in these three victims was secondary to apnoea. One may be tempted to draw one more conclusion. The affected individuals were young with a potentially healthy heart. The fact that these individuals were found in a state of sudden cardiac arrest due to asystole may indicate that the cardiac arrest lasted for a prolonged amount of time. Most frequently, cardiac arrest in such young individuals occurs as a result of ventricular fibrillation. Although this possibility exists, such prolonged delay of resuscitation and extent of injury could have facilitated the transformation of ventricular fibrillations into asystole. When analyzing other casualties and their injuries, hematomas of the thorax, abdomen, and pelvis were primarily described. Other diagnosed injuries included: knee sprain, calcaneal fracture, rib fractures, cerebral shock, and abrasions of the body.

\section{SUMMARY}

Many conclusions can be drawn from the tragic events which took place at the UTP campus in Bydgoszcz. The party organized by the students qualified as a mass event: admission fees were charged and there was the unauthorized sale of alcohol $[5,6]$. Taking these two facts into account, this event should have been reported to local emergency services (EMS, Police and the Fire Department), as well as the Mayor of the city of Bydgoszcz, in order to receive authorization for the event to take place. The Provincial Emergency Medical Service (WSPR) in Bydgoszcz annually issues recommendations regarding the holding of mass events, based on the ordinance of the Minister of Health dated February 6,2012 , outlining the minimum medical coverage required for a mass event. Up until the day of the tragedy, the student government sporadically sent letters to the WSRP asking for their medical opinions and expertise with regards to holding events. As of today, virtually every student event is reported for review by the WSPR, even if it does not meet the criteria for a mass event. It is undeniable that the EMS teams were operating in a hazardous environment when deciding to enter the building with inadequate protection and support from the police and fire department. It should be noted that the crowd of people, especially one that had consumed a large amount of alcohol, made it very difficult not only to enter the building, but also impeded EMS teams from carrying out rescue procedures and frequently distracted medical personnel even during cardiopulmonary resuscitations. Practically until the end of the rescue operation, no leaders from the police department or fire department were available to assist the EMS teams. Who should act as the leader in such situations? We will leave that for the reader to decide. Regarding the onsite medical director, it should be the responsibility of the leader of the first EMS team to arrive onsite to take on this role until the very end of the operation. Handing over leadership duties to another person is always connected to a loss of time and may cause many misunderstandings. The 
only situation which is an exception to this rule is when the leader of the first EMS team to arrive is not able to manage the situation and his/her role as the onsite medical coordinator. As for the situation described earlier, when the fire department contacted the medical dispatcher asking for more ambulances and resources, in the opinion of the authors of this paper, this behaviour has no place in such circumstances. If the medical dispatcher has an onsite medical coordinator and is in constant contact with them, the dispatcher knows best how many resources are required for the scene of the event. In addition, the false information given to the medical dispatcher from the fire department regarding the presence of 7 resuscitations, when in fact it was known that there were only 3 resuscitations, caused unnecessary chaos and confusion in the medical dispatcher's office. In the opinion of the authors of this paper, the use of pepper spray was not warranted and only escalated the situation in the conjoining hallway and caused more panic and chaos. The lack of radio contact between the medical dispatcher's office, EMS teams and the Emergency Department at WSK $X$ in Bydgoszcz unnecessarily complicated communications and prolonged the time necessary to convey vital information. As usual with such mass events, there is a lack of the free flow of information and radio communication between the three main emergency services; EMS, Police and Fire Departments. It is important to remember that in Bydgoszcz, such channels exist and are designed for exactly such situations, for example channel "Gopło". It should also be remembered that all persons who suffered injuries, as well as the families of the deceased, require mandatory psychological care and support. We do not only treat physical injuries to the body, while the mental health of these people is not any less important. Practice, practice and once again practice. There is no such thing as enough practice. Events such as this, which qualify as a mass casualty event, require that emergency personnel not only possess a large amount of medical knowledge, but also to have exceptional organizational skills. Of course, although many of these training exercises happen during the year, of concern is that even if everyone involved in the exercise knows what the nature of the event will entail, how many people will be injured, and where the injured will be, the outcomes are always poor. It is important to train in the most realistic conditions, using the skills and resources of all personnel involved. One cannot forget about the fact that hospital emergency departments must realistically take part in these exercises. Only then can emergency personnel get an accurate sense of a real mass casualty event. Also not to be forgotten, is the debriefing after such exercises, in order to discuss what was done well, but more importantly, what was door poorly and how it could be improved.

In conclusion, it is important to remember two other victims of this event. Charges were laid against the head of the student government of the University of Technology and Nature in Bydgoszcz, who was deemed responsible for the organization of the "shakening" party. She is facing up to eight years in prison. The regional procurator of Bydgoszcz-North charges her with endangering the health and lives of many people and organizing a mass event without permission to sell alcohol. The rector of the university is charged with failure to perform his duties. According to the prosecutor, the rector did not provide a secure environment for the event, nor did he create procedures allowing employees of the university to safely organize a mass event. He may serve up to three years in prison, and upon hearing the charges, he pleaded not guilty, refusing to testify.

Conflict of interest: None declared.

\section{REFERENCES}

1. Ciećkiewicz J. Ratownictwo medyczne w wypadkach masowych. Górnicki Wydawnictwo Medyczne, Wrocław 2010.

2. Mackway-Jones K. Triage. Ratunkowa segregacja medyczna. Elsevier Urban \& Partner, Wrocław 2016.

3. Parszowski S, Kruczyński A. Imprezy masowe. Organizacja, bezpieczeństwo, dobre praktyki. Wydawnictwo Difin, Warszawa 2015.

4. Zawadzki A. Medycyna ratunkowa i katastrof. Wydawnictwo Lekarskie PZWL, Warszawa 2011.

5. Dz.U. 2009 nr 62 poz. 504 - Ustawa z dnia 20 marca 2009 r. 0 bezpieczeństwie imprez masowych.

6. Rozporządzenie ministra zdrowia z dnia 6 lutego 2012 r. w sprawie minimalnych wymagań dotyczących zabezpieczenia pod względem medycznym imprezy masowej. 